\title{
The Discursive Construction of Online Corporate Identities through Corporate Websites
}

\author{
Fangmin Sun \\ Business School \\ Huanggang Normal University \\ Hubei 438000, China
}

\author{
Youhua $\mathrm{Fu}^{*}$ \\ Editorial Department of University Journal \\ Huanggang Normal University \\ Hubei 438000, China \\ * Corresponding author's E-mail: fuyouhua@hgnu.edu.cn
}

\begin{abstract}
This paper is proposed to examine the discursive construction of online corporate identities by analyzing corporate websites under the framework of Systematic Functional Multimodal Discourse Analysis (SF-MDA).Viewed as a kind of hypermodal discourse, websites can index the social practices and are also construed by the socio-cultural context in which the practices occur. Particularly, the corporate websites provide valid source to analyze the practices of constructing corporate identities when companies are searching for larger market share in both local and global markets. Based on the case analysis of Chinese companies, efforts are taken to investigate how corporate websites can help to mediate corporate identities in the era of globalization and what identities are constructed online.
\end{abstract}

Keywords-multimodal discourse analysis; corporate identity; corporate websites; case study; globalization; Chinese companies

\section{INTRODUCTION}

The topic of corporate identity has attracted an increasingly diverse scholarly interest in recent years. In the field of marketing and management, it is widely acknowledged that the concept of corporate identity is multidimensional, and is under the influence of both internal and external factors [1][11]. With the advent of internet, global companies are able to promote themselves and their products through the corporate website. Since corporate website can be compared to a virtual storefront of the company[2], the way a company presents itself through its corporate website directly affects its online corporate identity [9]. Moreover, from the perspective of linguists, it is suggested that the integration of different semiotic resources can be strategically applied to represent and construct social identities for both individuals and organizations. However, relative researches in business context concerning corporate identities are rather limited.

Just as an individual performs a self through discursive means, so can organizational entities. The practice of constructing an identity relies on a variety of methods such as the employment of lexical units and syntactic devices. But it is not limited to linguistic methods. It has been proved that other semiotic modes also play an increasingly important role in constructing and displaying a self so that the analysis of identity construction must incorporate a multimodal analysis.

Multimodality refers to modes of representation beyond verbal resources to include non-verbal semiotic resources such

This study was supported by "the Humanities and Social Science Project of Hubei Provincial Department of Education” (Project No.: 17D080). as image, music, space, etc. Multimodal representation has become omnipresent in today's 'compressed' world, as global flows of capital dissolve not only cultural and political boundaries but also semiotic boundaries[8][9], and the web environment increase multisemiotic complexity of the representations in corporate websites since digital technologies make possible the co-existence of various communication modes on a single web site. With their topological meaning potentials, those integrated semiotic resources contribute significantly to expanding the potential of corporate websites for effective communication about the corporate identities. Therefore, further investigation is needed into the discursive construction of corporate identities through their corporate websites.

\section{THEORETICAL BASIS}

The theoretical framework applied here is Systematic Functional Multimodal Discourse Analysis (SF-MDA), an extension of Systematic Functional Linguistics (SFL) framework developed by Halliday[5][6] into Multimodal Discourse Analysis (MDA) [12].

SFL views language as a social semiotic. Halliday (1994)[6] developed a metafunctional theory of language demonstrating meaning formations in terms of three distinct 'meta functions': ideational, interpersonal, and textual:

a) Ideational- concerned with experience and logical relations in the world

b) Interpersonal- concerned with the enactment of social relations

c) Textual-which organizes the ideational and interpersonal meanings into coherent and cohesive units of meaning

Halliday's tri-functional notion of meaning focused on texts as embodiments of social processes rather than formal grammatical sentences and thereby emphasized the socially meaningful role of texts.

It is considered as a strong and effective theory in the exploration of online corporate identity construction for two reasons: first, SF-MDA has the advantage for studies of hypermodal texts in its focus on meaning, which has extended beyond language dimension, to the study of images, gesture, sound and other semiotics, and their interaction of different 
semiotic resources in multimodal texts[13]. Second, SF-MDA emphasizes the social semiotic concept of texts as "a structure of message or message traces which has a socially ascribed unity"[7]. Therefore it has been proved adaptable to hypermedia discourse analysis and offered a fuller explanation to the construction of identities.

Besides, while website texts offer corporations ample space and possibilities to express themselves by using multiple semiotic resources such as audio, video, text, image, graphic and hyperlinks, the globally available internet also inevitably presents challenges in coding and decoding these web representations. Significant differences are found, for example, in the way companies' websites vary across countries. The reasons rest not solely with the constraints of technology, but are deeply interwoven with the broader political, economic and socio-cultural contexts.

To form a comprehensive picture of the various semiotic dimensions through which corporations construct identities in their websites, the multimodal analysis of homepages is undertaken using Zhang and O'Halloran's model[14] which is based on the premise that homepages fulfill two basic functions: (1) to introduce the user to the general content of the websites, which is defined as reading mode; (2) to provide access to the site through navigation tools that take the reader deeper into the website via clickable items on the homepage, which is defined as navigating mode. This two-dimensional model enables us a fuller understanding of how semiotic resources function hypermodally to construe meaning in the homepage.

\section{CASE STUDY}

As the world's second largest economy, China is taking an increasingly active role in the world stage. Chinese companies are now granted with more opportunities to 'go global'. Meanwhile, there are also many tend to 'bring in' and make innovations with Chinese originality in order to differentiate themselves in the global market. Therefore, it is often found that some big Chinese companies try to position themselves somewhere between being global and local in the era of globalization. This case analysis chooses Bank of China and Huawei, two well-known Chinese companies as the research objects. All the content are sourced from the companies' websites: Bank of China at http://www.boc.cn; Huawei at http://www.huawei.com/en.

These webpages are composed by reading modes such as language, image, typography, etc. and navigation modes such as hyperlinks. These semiotic resources can be strategically used to construct the corporate social identities. In what follows, the paper mainly focuses on the reading modes on these corporate homepages since visitors to a homepage normally first read or at least scan the page before their navigation. Moreover, a further anlaysis of the systemic choices of these semiotic resources can help us better understand how the three social functions are realized and finally form the corporate identities through the webpage discourse.

\section{A. Language as a mediator of corporate identities}

The choice of language is a key element in the discursive construction of corporate identity in the age of globalization. First, it is noticed that a multilingual strategy is adopted by these two companies in a slightly different manner.

As shown in Fig. 1, there is a fairly rigid equation between language and country in Huawei's strategy of globalization to facilitate target markets. However, its diversification of linguistic choices only limited to the scale of central languages instead of peripheral ones, reflecting its practical market-driven orientation as a "going-global" private company.

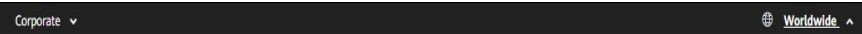

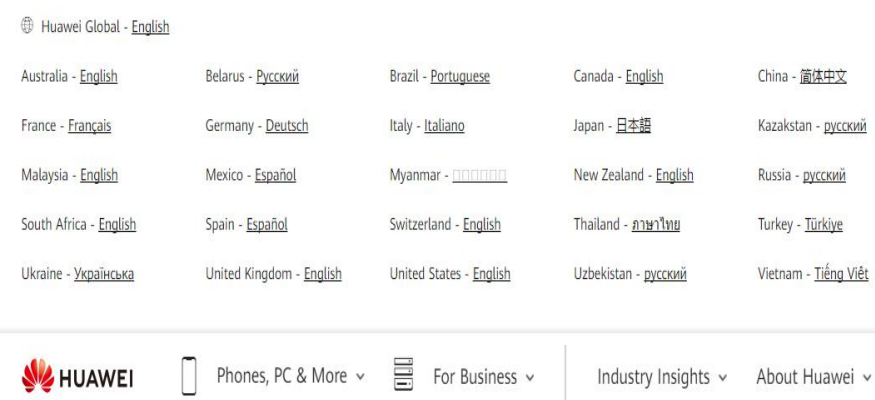

Fig. 1. Global Website Map of Huawei Corporation

On the contrary, Bank of China (as shown in Fig. 2), being positioned as China's most internationalized and diversified bank, is committed to promote its Chinese national identity in the global stage by using the simplified Chinese in its global site while keeping a site in traditional Chinese to manifest Taiwan as an indispensable part of China. Also, the main website contains a link to its English site because English is considered as an international language and is a symbol of globalization.

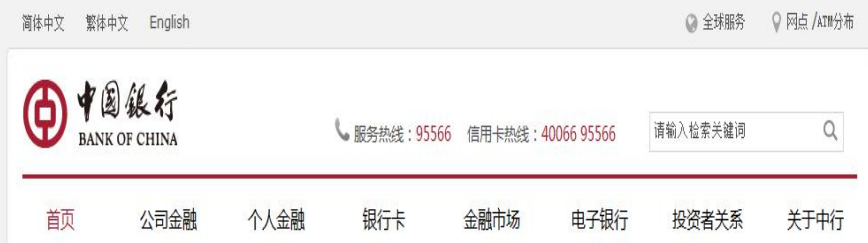

Fig. 2. Global Website Map of the Bank of China

Second, the use of personal pronouns indicates the discursive construction of corporate identity. Pronouns function as a most suitable grammatical category for the expression and manipulation of social relations, status and power.

It is found that Huawei uses the first personal plural form 'we' extensively in 'Corporate Introduction' and at the beginning of each bullet sentences, such as 'We create value for our customers', 'We promote industry development', 'We drive economic growth', and so on. This discursive manipulation is strategic as it gives an impression that Huawe takes the lead to involve everyone into the process of building a better world. Comparatively, Bank of China chooses to introduce itself from a third person standpoint. By cautiously 
addressing itself in its full name 'Bank of China' whenever possible, it reinforces the official image as 'China's bank'.
TABLE I presents a clearer comparison of the self-positing strategies by Huawei and the Bank of China respectively, through the information collected from their corporate websites.

TABLE I. SAMPLE COMPANIES AND THEIR SELF-POSITIONING OF CORPORATE IDENTITY

\begin{tabular}{|c|c|c|c|c|c|}
\hline $\begin{array}{c}\text { Company } \\
\text { name }\end{array}$ & $\begin{array}{c}\text { Product or } \\
\text { service }\end{array}$ & Corporate type & $\begin{array}{c}\text { Target consumers and } \\
\text { markets }\end{array}$ & $\begin{array}{c}\text { Corporate } \\
\text { Vision }\end{array}$ \\
\hline corporate identity
\end{tabular}

\section{B. Images as the mediator of corporate identities}

For most people, images sustain remembrance when words have long been forgotten, and communicate more readily to the public than language. There are different types of images presented in a corporate website. In what follows, the logos and images displayed at the central or top banner of the home pages are taken for analysis to examine how they are used to the mediator and convey corporate identities.

First, logos are considered as one of the most visible sign that create in the viewer's mind connections between visual design and the organization ${ }^{[14]}$. The logo is always found on the corporate homepage, normally on the top left part of the web page, which is an important semiotic resource for representing the company to current and prospective customers Huawei maintains tradition by having a flower image as part of its logo (as shown in Fig. 3), which represents the flourish of its business. The style of the flower petals is abstract, geometric and graphically simple. It is global in character since it is not associated with any particular person or place. The logo for Bank of China (as shown in Fig. 4) takes the shape of Chinese ancient money and Chinese letter "zhong" as its basic design. The iconic ancient money represents the financial services of bank, and the letter "zhong" stands for China. Therefore, it is typical Chinese style and that create familiarity between the Chinese customers.

\section{QVE HUAWEI}

Fig. 3. Logo of Huwei

\section{(C) 中国银行}

Fig. 4. Logo of the Bank of China

Second, an analysis of the interpersonal functions of the images displayed at the central or top banner of the corporate homepages offers a way to understand how different types of company position itself to the general public. Kress and van Leeuwen (2006)[8] identify three main factors in the visual realizations of interactive meanings: (i) contact which is realized through the gaze at the viewer, (ii) social distance which is realized through the length of shot, and (iii) point of view which is realized through the angle of the shot. The choices for contact, social distance, and point of view in the homepage images for Huawei and Bank of China are shown in TABLE II.

TABLE II. THE IMAGES COMPARISON BETWEEN HOMEPAGES OF HUAWEI AND THE BANK OF CHINA WEBSITES

\begin{tabular}{|c|c|c|c|c|c|}
\hline $\begin{array}{c}\text { Corporate } \\
\text { name }\end{array}$ & $\begin{array}{c}\text { Number of } \\
\text { personal } \\
\text { images }\end{array}$ & Contact & $\begin{array}{c}\text { Social } \\
\text { distance }\end{array}$ & $\begin{array}{c}\text { Point of } \\
\text { view }\end{array}$ & $\begin{array}{c}\text { Indication of } \\
\text { relationship }\end{array}$ \\
\hline Huawei & 1 & $\begin{array}{c}\text { All no direct } \\
\text { gaze }\end{array}$ & $\begin{array}{c}\text { Far social } \\
\text { distance }\end{array}$ & $\begin{array}{c}\text { Horizontal } \\
\text { and } \\
\text { oblique } \\
\text { angles }\end{array}$ & $\begin{array}{c}\text { Offer } \\
\text { information }\end{array}$ \\
\hline $\begin{array}{c}\text { Bank of } \\
\text { China }\end{array}$ & 4 & $\begin{array}{c}1 \text { direct gaze, } \\
3 \text { no direct } \\
\text { gaze }\end{array}$ & $\begin{array}{c}\text { Far } \\
\text { personal } \\
\text { distance }\end{array}$ & $\begin{array}{c}\text { Horizontal } \\
\text { and } \\
\text { oblique } \\
\text { angles }\end{array}$ & $\begin{array}{c}\text { Offer } \\
\text { information }\end{array}$ \\
\hline
\end{tabular}

The results in TABLE II for 'contact' realized through gaze in the images suggest that these two Chinese companies tend to be information 'offering' rather than 'demanding' in the specific content displayed by the image. The social distance set by Huawei is far since it aims at the global markets, while Bank of China remains in a relatively close relationship with the Chinese customers. Besides, the bank of China intends to build its public image as a model state-owned company, so that it conveys through the choice of images in its homepage to keep a far personal distance. However, it is hard to make any conclusions about whether and how the selfpositioning strategies used by these two types of companies are different, unless more sample images are being analyzed both diachronically and synchronically.

\section{CONCLUSION}

This article intends to justify the need for an in-depth discourse analysis of the construction of corporate identities through corporate websites: firstly, it will enable us a closer look at how the hypertexts of websites might help companies to utilize multi-semiotic resources in the construction of identities for themselves and their target customers. Secondly, the analytical insights from within the linguistic frameworks will be useful complementary to current research on corporate identities. Thirdly, In the age of globalization, the discursive power of identity construction should consider the 
intertwining and intersection between semiotic practice, identity and culture as websites can serve as a good starting point in semiotically reconstructing identities and reshaping relevant social practices. Also considering China as the world's second largest economy and Chinese internet users are burgeoning in recent years, the investigation of multimodal strategies used in the websites of Chinese companies can enrich the multimodal discourse analysis.

\section{REFERENCES}

[1] Argyriou, E., Kitchen, P. J. and Melewar, T. C. "The relationship between corporate websites and brand equity: A conceptual framework and research agenda". International Journal of Market Research, 48(5):575-599, 2006.

[2] Berthon, P., Pitt, L. F. and Watson, R. T. "The World Wide Web as an advertising medium: Toward an understanding of conversion efficiency". Journal of Advertising Research, 36(1): 43-54, 1996.

[3] Barthes, R. Image. Music. Text. London: Fontana, 1977.

[4] Fangmin Sun, "Meaning Constructed by Images in Cross-border Ebusiness Websites: A Case Study in China from Social-semiotic Perspective", Advances in Economics, Business and Management Research, 2017(3).
[5] Halliday, M.A.K. Language as Social Semiotic: The Social Interpretation of Language and Meaning. London: Arnold, 1978.

[6] Halliday, M.A.K. An Introduction to Functional Grammar. London: Arnold, 1994

[7] Hodge, Robert, and G. Kress. Social Semiotics, Style and Ideology. Sociolinguistics. 1997.

[8] Gunther Kress, Multimodality: A Social Semiotic Approach to Contemporary Communication, London: Routledge, 2010.

[9] Gunther Kress and Theo van Leeuwen, Reading Images: The Grammar of Visual Design, 2nd ed., London: Routledge, 2006.

[10] Maynard, M., and Tian, Y. "Between global and glocal: Content analysis of the Chinese web sites of the 100 top global brands". Public Relations Review, 30(3): 285-291, 2004.

[11] Melewar, T. C. "Determinants of the corporate identity construct: A review of the literature". Journal of Marketing Communications, 9(4): 195-220, 2003.

[12] O'Halloran KL. "Systemic functional-multimodal discourse analysis (SF-MDA): Constructing ideational meaning using language and visual imagery". Visual Communication, 7(4): 443-475, 2008.

[13] O'Halloran, KL. (Ed.). Multimodal Discourse Analysis. London/New York: Continuum. 2004

[14] Zhang, Yiqiong, and K. L. O'Halloran. “"Toward a global knowledge enterprise': university websites as portals to the ongoing marketization of higher education". Critical Discourse Studies. 10(4):468-485, 2013. 